\title{
Foreward
}

\section{Welcome to Volume 2 of Journal of Medical Research and Innovation}

\author{
Varshil Mehta \\ Editor in Chief, Journal of Medical Research and Innovation \\ Address for correspondence: Varshil Mehta. Editor in Chief, Journal of Medical Research and \\ Innovation. E-mail: varshil91@gmail.com
}

\begin{abstract}
It is my pleasure to introduce the first issue of volume 2 from Journal of Medical Research and Innovation (JMRI). The entire JMRI team is excited to begin our $2^{\text {nd }}$ year journey of publishing good quality research from across all the medical-related disciplines, all the way from the bench to the bedside. Although we have some quite interesting things planned for 2018 , in this Foreword, we will have a look back over some important highlights from volume 1 and some achievements of JMRI from the year 2017.
\end{abstract}

Keywords: New year, Look back, Publishing

Quick Access Code

Doi: $10.15419 / j m r i .106$

Publication history:

Received: 08-12-2017

Published: 09-12-2017

\section{Copyright: Mehta. V} This is an open access article distributed under the terms of the Creative Commons Attribution License CC-BY 4.0., which permits unrestricted use, distribution, and reproduction in any medium, provided the original author and source are credited.

Funding: NIL Conflict of Interest: NIL

Direct link: https:// jmri.org.in/jmri/article/ view/106

Non-Peer reviewed

\section{Foreword}

First and foremost, I would like to thank each and every one, who has helped to make the Journal of Medical Research and Innovation (JMRI) a successful and well referred medical journal. With the launch of the second volume, I would like to share some important and salient features of JMRI.

Let us first talk about the site. The journal's site was coded by me with some help from Dr. Vitaliy (who is also on our editorial board) with few members and staff from Open Journal System from Public Knowledge Project. At an earlier stage (just after the launch), it was not very professional and eye catchy. However, now, the site looks fantastic.

We started with my editorial on "Should research be made compulsory in medical schools?" ${ }^{[1]}$ which was well referred throughout the world. However, the notable papers of volume one were the following articles: "Health Problems and Health Care Seeking Behavior of Rohingya Refugees; ${ }^{[2] ”}$ "probiotics: An Adjuvant therapy for D-Galactoseinduced Alzheimer's disease; [3]" and "Universal Health Coverage: A burning need for developing countries. [4]" In "Health Problems and Health Care Seeking Behavior of Rohingya Refugees," the authors have mentioned about the atrocities faced by Rohingya refugees with regard to health care. It is quite sad to see that they are not even getting basic health services. Hence, this paper served as an eye opener for the health authorities. The article "Probiotics: An Adjuvant therapy for D-Galactose-induced Alzheimer's disease" was the most cited article when self-citations were excluded. "Universal Health Coverage: A burning need for developing countries" was the most cited article, but most of them were self-citations. With the second volume launch, JMRI was already in the limelight. We were now able to publish the full text XML, HTML, and PDF. A paper by Mandal and Sahi, on Probiotics for diarrhea in children was the most well-received paper. ${ }^{[5]}$ The authors showed the importance of probiotics usage in pediatric patients having diarrhea. Another such stellar paper published in the third issue showed the benefits of using improved cooking stove on maternal health in Bangladesh. ${ }^{[6]}$

Apart from publishing good quality articles, we also improved our indexes. We got indexed in Research gate, BASE, CNKI Scholar, Google Scholar, Index Copernicus, PKP Index, Worldcat and Zenodo. We also won the November contest at ScienceOpen, and thus got indexed with them as well. We also won the "Best Upcoming Medical Journal" Award from Indian Health 
Professional Awards. It was indeed a very good year for us. Talking about the statistics, we received approximately 1200 unique visitors every month with a page view of approximately 8000 per month. The acceptance rate was approximately $66 \%$. From $8^{\text {th }}$ October, we began open peer review system which helps us to provide an open and transparent peer review system. I would also like to thank Dr. Phuc Pham for sponsoring us with regard to generation of crossRef DOI's.

Last but not the least; we want to appreciate all our editorial board members and reviewers for helping us in every way possible.

Looking forward to 2018, we hope and promise to deliver the best open access publishing experience in future for free to everyone. We hope that JMRI will be able to fulfill your expectations and prove to be a useful reading source for medical world.

\section{REFERENCES}

1. Mehta V. Should research be made compulsory in medical school? J Med Res Innov 2017;1:1-3.

2. Masud A, Ahmed MS, Sultana MR, Alam SI, Kabir R, Arafat SY, Papadopoulos K. Health problems and health care seeking behaviour of rohingya refugees. J Med Res Innov 2017;1:21-9.

3. Mehta V, Bhatt K, Desai N, Naik M. Probiotics: An adjuvant therapy for D-Galactose induced Alzheimer's disease. J Med Res Innov 2017;1:30-3.

4. Zaman SB, Hossain N. Universal health coverage: A burning need for developing countries. J Med Res Innov 2017;1:18-20.

5. Mandal A, Sahi P. Probiotics for diarrhea in children. J Med Res Innov 2017;1:AV5-12.

6. Zaman SB, Hossain N, Khandker S. Impact of improved cooking stove on maternal health in rural Bangladesh: $A$ quasi-experimental study. J Med Res Innov 2017;1:1-9. 